\title{
Um estudo comparativo das disparidades salariais entre os migrantes nordestinos e os nativos paulistas no mercado de trabalho de São Paulo
}

Ricardo Schmidt Filho ${ }^{1}$

Paulo Aguiar do Monte ${ }^{2}$

Marcio Miceli ${ }^{3}$

Resumo: A partir da constatação do intenso fluxo migratório do Nordeste para o Sudeste do País, especificamente, o Estado de São Paulo, este artigo busca verificar as condições de inserção dos trabalhadores nordestinos (migrantes) no mercado de trabalho de São Paulo. A temática em questão é analisar se os migrantes nordestinos têm as mesmas condições de trabalho (medida em termos de rendimento salarial) em relação aos nativos paulistas. Ademais, procurou-se verificar até que ponto uma maior permanência no Estado de destino (São Paulo) favorece a um aumento de salário e a redução dos diferenciais de rendimento existentes. Os resultados encontrados comprovam a existência de diferenciais salariais entre paulistas (nativos) e nordestinos (migrantes) a favor do primeiro, contudo evidenciam uma redução desta diferença ao longo da permanência dos nordestinos em São Paulo.

Palavras-chave: migração; trabalho; salário.

\section{A comparative study of wage differentials between northeast migrants and native paulistas in the labor market of São Paulo}

\footnotetext{
Abstract: Given the intense migration flow from the northeast to the southeast of Brazil, specifically to the Sao Paulo state, this article tries to establish some of the working conditions of the northeastern migrant workers in Sao Paulo. The main question is to check whether the northeastern workers have the same working conditions (measured in wage terms) as the Sao Paulo natives. We also

1 Doutorando em Desenvolvimento Econômico da UFPR. E-mail: rschmidtfilho@hotmail.com.

2 Professor Adjunto do Departamento de Economia da UFPB. E-mail: pauloaguiardomonte@gmail.com.

3 Mestrando em Economia do Trabalho da UFPB. E-mail: marciomiceli@hotmail.com.
} 
SCHMIDT FILHO, R. \& DO MONTE, P. \& MICELI, M. Um estudo comparativo das disparidades...

check whether a prolonged stay in the state of Sao Paulo favors a wage rise and a reduction in working capacities between the two groups considered. The results suggest the existence of different wage rates between the Sao Paulo natives and the northern workers in favor of the first but also suggest that the prolonged stay in the state of Sao Paulo does reduce that difference.

Keywords: Migration; labor; wage.

JEL: J61，J21，J31

\section{Introdução}

A migração, há anos, vem sendo alvo de vários estudos no Brasil. Um dos aspectos relevantes para a ocorrência destes fluxos migratórios é a desigualdade regional advinda desde o período colonial quando se formaram diferentes economias regionais primário-exportadoras baseadas no trabalho escravo.

Segundo Cano (1997), superada a fase da escravidão e o conseqüente desenvolvimento das formas capitalistas de produção consolidaram um elevado desequilíbrio regional no Brasil, culminando na concentração da produção industrial do País na Região Sudeste (especialmente em São Paulo) na relação de forte predominância do complexo econômico paulista sobre as demais regiões, imprimindo-lhes, em grande medida, uma relação comercial de 'centro-periferia'.

Devido a sua força econômica - configurada na maior renda salarial e nos indicadores sociais apresentados -, o Estado de São Paulo tornouse, historicamente, um receptor de diversos fluxos migratórios, notadamente o de trabalhadores da Região Nordeste. Mediante esta constatação, busca-se estudar determinados aspectos relativos à inserção no mercado de trabalho de São Paulo dos trabalhadores nordestinos que migraram para este Estado da Federação. A questão crucial é analisar se os migrantes nordestinos têm as mesmas condições de trabalho (medida em termos de rendimento salarial) em relação aos nativos paulistas e, com o passar do tempo, se estas condições são melhoradas/pioradas. As informações utilizadas neste estudo são advindas da Pesquisa Nacional por Amostra a Domicílio (PNAD) de 2005.

De forma geral, as inferências obtidas apontam que, dentre os diversos fatores (educação, sexo, faixa etária, setor de atividade, ocupação) que estão associados aos diferenciais de salário capital humano do trabalhador, o Estado de origem do trabalhador também têm significativa influência na questão salarial. As evidências também sugerem que o maior tempo de permanência do migrante nordestino no Estado de São Paulo auxilia na redução das disparidades de salariais existente quando se compara o trabalhador paulista (nativo) e o nordestino (migrante). 
Para alcançar este objetivo, o artigo foi construído com sete tópicos, incluindo esta introdução. No segundo tópico busca-se estudar o fenômeno da migração no contexto nacional, com ênfase no fluxo NordesteSudeste; no terceiro, procuram-se explicações para a determinação dos rendimentos dos trabalhadores segundo as principais teorias que envolvem o fenômeno da migração e da oferta de trabalho; no quarto é enfocada a questão metodológica acerca da captação dos dados e do modelo econométrico aplicado; no quinto analisam-se os dados extraídos para a amostra de nordestinos e paulistas; no sexto são descritos os resultados das regressões e, no último, reportam-se às considerações finais.

\section{Breve relato do fenômeno da migração interregional no contexto brasileiro}

O fenômeno da migração no Brasil tem sido foco de intenso debate dentro das ciências sociais. Parcela significativa dos especialistas no assunto compreende-no como fruto do avanço das desigualdades regionais, motivadas pela incorporação de novos espaços do capitalismo nacional, arquitetado em um processo de desenvolvimento industrial tardio e concentrador do ponto de vista geográfico, o qual veio a fortalecer uma única região brasileira em detrimento das demais. (Silva Netto Júnior, 2003).

Pode-se atribuir a década de 30 como o ponto de partida para a intensificação do processo migratório brasileiro. Tais deslocamentos estavam intimamente ligados ao nascimento e evolução do processo de industrialização nacional, desenvolvido embrionariamente na Região Sudeste, em substituição as atividades primário-exportadoras, as quais desfrutavam de grande participação na estrutura produtiva nacional, inaugurando um período onde a atividade agrícola, aos poucos, foi reduzindo a sua participação relativa na composição do Produto Interno BrutoPIB nacional. (Targino, 1987)

Segundo Garcia Jr. (1989), as migrações da Região Nordeste para o Sudeste eram as mais comuns, devido aos maiores salários ofertados pela região onde o capitalismo industrial se desenvolvia a passos largos, bem como ao progresso dos meios de transporte, o qual se tornava cada vez mais evidente, com o desenvolvimento da malha rodoviária, construída com o objetivo de favorecer o escoamento da produção do mercado nacional e a circulação de pessoas entre as cinco regiões brasileiras. Muitas destas viagens realizadas por nordestinos que vislumbravam alcançar, em uma outra região, a oportunidade de obtenção de uma vida 
mais digna e com menos carências sociais eram financiadas por industriais da Região Sudeste, os quais lhes asseguravam emprego ao chegar.

No contexto nacional, o Nordeste se caracterizava como uma região subdesenvolvida, de forte concentração demográfica, e que, historicamente apresentava saldos migratórios negativos em relação às demais regiões brasileiras. Tradicionalmente, os deslocamentos espaciais da população nordestina eram explicados a partir de fatores climáticos. Gradativamente, esta concepção foi sendo repensada. Segundo Targino (1987), nos anos cinqüenta, o problema não mais perpassava pelas secas periódicas, mas se devia ao crescimento industrial do centro-sul região próspera e enorme demandante de mão-de-obra. A partir de então, as migrações passam a sofrer de forma mais intensa as conseqüências da integração do mercado de trabalho a nível nacional e a crescente expansão do setor industrial brasileiro, promovendo uma alteração nas características econômicas e geográficas do país, a partir de grandes deslocamentos espaciais de indivíduos, notadamente da Região Nordeste rumo ao pólo mais dinâmico da economia brasileira, concentrado na Região Sudeste. (Silva Netto Júnior, 2003).

A concentração espacial das atividades urbano-industriais na Região Sudeste fez do eixo Rio - São Paulo, o centro capitalista nacional o qual se tornou uma importante fonte receptora de mão-de-obra fazendo eclodir nestas duas cidades uma classe proletária urbana. Diante deste novo cenário o processo de migração brasileiro ganha forte destaque no que diz respeito à realocação espacial da população, tornando cada vez mais claro que a análise da dinâmica migratória em território brasileiro não poderia realizar-se separadamente do processo de desenvolvimento e expansão do capitalismo nacional, pois era nítida a relação entre a urbanização e a aceleração dos fluxos migratórios.

Dentro desta concepção, a migração passa a ser compreendida como resultado de um rearranjo espacial dos trabalhadores das zonas economicamente periféricas para as zonas mais robustas, onde o capitalismo encontrava-se mais desenvolvido, influenciando decisivamente na acentuação das desigualdades regionais. Apresentava-se, assim, uma das características mais determinantes do modo de produção capitalista, calcado na forma desigual que se processa a sua expansão em relação aos diferentes espaços geográficos (Singer, 1981).

Os Quadros 1 e 2 abaixo servem para ilustrar este período de crescente intensidade migratória, tanto de caráter interestadual quanto interregional. Pode-se observar um considerável crescimento na taxa de intensidade migratória durante o período visto que, em 1950, 9,86\% da população brasileira migravam para outros estados em busca de maiores oportunidades, enquanto que no ano 2000, esta taxa quase 
SCHMIDT FILHO, R. \& DO MONTE, P. \& MICELI, M. Um estudo comparativo das disparidades...

duplica, alcançando o patamar de $15,33 \%$ - embora tenha se verificado um decréscimo no referente à taxa de crescimento das migrações interestaduais. Por sua vez, o quadro seguinte revela um crescimento, tanto em termos absolutos como relativos, do número de pessoas que migraram entre regiões no período de 1950 a 2000. Em 1950, as migrações inter-regionais representavam apenas $3,96 \%$ do montante populacional

TABELA 1 - POPULAÇÃO RESIDENTE, MIGRANTES INTERESTADUAIS, INTENSIDADE MIGRATÓRIA E TAXA DE CRESCIMENTO DOS MIGRANTES, PARA O BRASIL - 1950-2000

\begin{tabular}{lcccc}
\hline Ano & $\begin{array}{l}\text { População } \\
\text { residente (1) }\end{array}$ & $\begin{array}{l}\text { Migrantes } \\
\text { interestaduais (2) }\end{array}$ & $(2) /(1)(\%)$ & $\begin{array}{l}\text { Taxa de crescimento das } \\
\text { migrações interestaduais (\%) }\end{array}$ \\
\hline 1950 & 51.944 .397 & 5.124 .083 & 9,86 & - \\
1960 & 70.070 .457 & 8.184 .519 & 11,68 & 59,73 \\
1970 & 93.139 .037 & 12.345 .337 & 13,25 & 50,84 \\
1980 & 121.611 .375 & 18.203 .818 & 14,97 & 47,46 \\
1991 & 149.926 .149 & 21.784 .851 & 14,53 & 19,67 \\
2000 & 170.143 .121 & 26.083 .543 & 15,33 & 19,73 \\
\hline \multicolumn{2}{l}{ Fonte: IBGE - Censos Demográficos. }
\end{tabular}

TABELA 2 - BRASIL. POPULAÇÃO RESIDENTE, MIGRANTES INTERREGIONAIS, RELAÇÃO ENTRE MIGRANTES INTER-REGIONAIS E POPULAÇÃO RESIDENTE, RELAÇÃO ENTRE MIGRANTES INTER-REGIONAIS E MIGRANTES INTERESTADUAIS - 1950-2000

\begin{tabular}{|c|c|c|c|c|c|c|c|c|c|c|c|c|}
\hline $\begin{array}{l}\text { Investimento e } \\
\text { Financiamento }\end{array}$ & 1990 & 1991 & 1992 & 1993 & 1994 & 1995 & 1996 & 19971998 & 1999 & 2000 & 2001 & 2002 \\
\hline Investimento & 100,0 & 100,0 & 100,0 & 100,0 & 100,0 & 100,0 & 100,0 & $100,0100,0$ & 100,0 & 100,0 & 100,0 & 100,0 \\
\hline Estatal & 66,1 & 66,4 & 68,1 & 60,6 & 56,4 & 54,4 & 52,4 & $52,5 \quad 54,1$ & 53,4 & 50,1 & 47,3 & 43,7 \\
\hline Propriedade coletiva & 11,7 & 12,5 & 16,8 & 17,7 & 16,2 & 16,4 & 15,9 & $15,4 \quad 14,8$ & 14,5 & 14,6 & 14,2 & 13,7 \\
\hline Propriedade individual & 22,2 & 21,1 & 15,1 & 11,3 & 11,6 & 12,8 & 14,0 & $13,7 \quad 13,2$ & 14,1 & 14,3 & 14,6 & 14,5 \\
\hline Outros & - & - & - & 10,4 & 15,8 & 16,3 & 17,7 & $18,3 \quad 18,0$ & 18,0 & 21,0 & 23,9 & 28,1 \\
\hline Fontes de financiamento & 100,0 & 100,0 & 100,0 & 100,0 & 100,0 & 100,0 & 100,0 & $100,0100,0$ & 100,0 & 100,0 & 100,0 & 100,0 \\
\hline Estatal & 8,7 & 6,8 & 4,3 & 3,7 & 3,0 & 3,0 & 2,7 & 2,8 & 6,2 & 6,4 & 6,7 & 7,0 \\
\hline Empréstimos domésticos & 19,6 & 23,5 & 27,4 & 23,5 & 22,4 & 20,5 & 19,6 & $18,9 \quad 19,3$ & 19,2 & 20,3 & 19,1 & 19,7 \\
\hline Investimento estrangeiro & 6,3 & 5,7 & 5,8 & 7,3 & 9,9 & 11,2 & 11,8 & 10,6 & 6,7 & 5,1 & 4,6 & 4,6 \\
\hline Outros & 65,4 & 64,0 & 62,5 & 65,5 & 64,7 & 65,3 & 66,0 & $67,7 \quad 67,4$ & 67,8 & 68,2 & 69,7 & 68,7 \\
\hline Investimento / PIB (em \%) & 24,4 & 25,9 & 30,3 & 37,7 & 36,4 & 34,4 & 33,8 & $33,8 \quad 33,8$ & 33,8 & 33,8 & 38,2 & 41,2 \\
\hline
\end{tabular}


existente no país. Em 1960, 1970 e 1980 verifica-se uma elevação destes números, os quais alcançam, respectivamente, o patamar de $6,31 \%$, $7,47 \%$ e $8,91 \%$. Em 1991, o número de migrações entre regiões se estabiliza, voltando a se expandir em 2000 , onde finalmente alcança a casa dos dois dígitos.

Percebe-se, portanto, que o fenômeno da migração ainda persiste no Brasil. A sua intensidade é comprovada através dos censos demográficos do IBGE de 1980, 1990 e 2000, onde se verifica um fluxo migratório bastante intenso de cidadãos que residiam no Nordeste em direção à Região Sudeste. Vale salientar que nenhuma outra região recebeu tantos nordestinos como a Sudeste, constituindo-se, portanto, um grande pólo de atração de mão-de-obra do Nordeste.

Entretanto, alguns estudos, dentre os quais Brito e Carvalho (2006) e Cunha (2006), já têm observado a redução desta tendência migratória a partir século XXI. Especificamente, em São Paulo, a partir de 2002, o número de emigrantes superou o de imigrantes, indicando, portanto uma tendência de reversão do fluxo migratório para este grande centro urbano. A grande novidade do período recente está na mudança dos fluxos migratórios para o Centro-Oeste e para o interior de São Paulo devido à mudança da distribuição espacial da atividade econômica, sobretudo da Indústria.

\section{A migração e o mercado de trabalho}

Existem diversos fatores associados ao fenômeno da migração. Os modelos teóricos inspirados em escola de orientação clássica ou históricoestrutural atribuem aos desequilíbrios espaciais de natureza sócio-econômica (desigualdades das taxas de crescimento, dos níveis salariais, da maior oferta de empregos, serviços públicos, políticas sociais) a determinação básica dos fluxos migratórios. (Salim, 1992). (Baeninger, 1999).

De uma forma geral, a literatura sobre o tema costuma abordar os movimentos migratórios a partir de dois enfoques: o neoclássico e o histórico-cultural. Sobre o primeiro, parte-se da premissa que a decisão de migrar é concebida sob o ponto de vista micro (individual) através da ponderação racional dos custos e benefícios esperados; enquanto o enfoque histórico-cultural considera o contexto econômico e social mais importante para se analisar as causas da migração do que a simples análise de custos e benefícios, sugerida pela abordagem micro.

Uma vez que se compreende o fenômeno da migração interregional no Brasil, em especial a que ocorre entre as regiões Nordeste e Sudeste do 
País, como uma conseqüência de fatores econômicos, é importante também enfocar a relação entre este fato e seus impactos no mercado de trabalho. Tendo como base a análise neoclássica, a interação entre agentes ofertantes, migrantes ou nativos, e demandantes no mercado de trabalho têm como foco principal a determinação do preço da mercadoria transacionada neste mercado (salário) que será determinada pelo livre jogo de oferta e demanda de trabalho. No entanto, estas colocações são feitas em uma perspectiva microeconômica neoclássica, assumindo a homogeneidade da mão-de-obra. Segundo Lima (1980), a mercadoria trabalho não possui o grau de homogeneização requerido para que ser tratada como um único bloco que pudesse ser agregado. Contudo, apesar do reconhecimento de que a mão-de-obra possui distintas qualidades esta continuou a ser tratada como um produto homogêneo e a ter seu preço determinado pelo encontro das duas curvas. Assim, por muito tempo, o mercado de trabalho pode ser compreendido como um conjunto de relações e interações entre firmas e trabalhadores que a nível agregado determina os níveis de emprego e salário e suas estruturas.

Diversas teorias procuram abordar a questão da inserção no mercado de trabalho, cada uma enfocando sob um determinado prisma a questão salarial. Um primeiro enfoque a ser citado reporta-se a questão da qualificação do trabalhador (educação, treinamento, experiência, migração - vista como indicador de ambição pessoal, onde o trabalhador dará o máximo de si para conseguir ingressar em boa situação ocupacional e maximizar os rendimentos do seu trabalho) como fator fundamental no incremento da produtividade e, consequentemente, na maior receita gerada ao empregador, influindo positivamente na maior aceitação do trabalhador no mercado de trabalho e no seu salário.

Uma segunda abordagem refere-se à estrutura social e suas desigualdades que, de acordo com Sorensen apud Biagioni (2006), podem definir o acesso a diferentes posições no mercado de trabalho: no mercado primário os postos possuem melhores rendimentos, condições de trabalho, estabilidade e possibilidade de ascensão ou no mercado secundário onde fatores como educação não significa, necessariamente, maior salário, onde os empregos são mais frágeis - os chamados 'bad jobs'. Assim, observa-se que podem existir diversos segmentos de mercados de trabalho, cada um possuindo características específicas principalmente quanto aos postos de trabalho. Um tipo de mercado (por exemplo, o mercado primário) seria identificado como aquele que concentra os empregos do setor moderno da economia, as ocupações que têm as características de hábitos de trabalho e emprego estáveis, salários relativamente altos, progresso técnico, produtividade alta e a existência de canais de promoção ocupacional dentro das próprias firmas. Por sua vez, o mercado secundário seria caracterizado por alta rotatividade da mão-de-obra, salários relativamente baixos, precárias condições de 
trabalho, estagnação tecnológica e baixa produtividade (Lima 1980; Correia \& Gomes Filho 1997).

Um terceiro enfoque pode ser pautado na crítica à hipótese de informação perfeita no mercado de trabalho visto que, para muitos estudiosos, as informações inacessíveis a todos os agentes, em virtude, na maioria das vezes, dos custos necessários a sua obtenção. Para Stigler (1962), o fato de a informação não ser livre faz com que o mercado não funcionasse em moldes de concorrência perfeita. Desta forma, tanto o demandante de mão-de-obra quanto o ofertante não possui informação completa sobre o mercado de trabalho, especificamente, sobre a produtividade e o desempenho profissional do ofertante (no caso do demandante) e sobre as oportunidades de emprego disponíveis e suas respectivas remunerações (no caso do ofertante). Neste contexto, um fator que pode minimizar esta falta de informação, para o caso dos migrantes, é o tempo de permanência na região/estado. Segundo Borjas (1999), o aumento do período de residência no local de migração ajuda no conhecimento acerca da comunicação e do mercado de trabalho.

Assim, o fenômeno da migração e seus impactos no mercado de trabalho, em especial, a determinação do salário, podem ser analisados sobre diferentes enfoques teóricos. Neste ensaio não está se procurando avaliar qual(is) abordagem(ns) encontra-se em consonância com a realidade empírica do fluxo migratório, apenas busca-se, através do aparato teórico, relacionar tal fenômeno à dinâmica do mercado de trabalho. Assim, a análise acerca das condições de do migrante nordestino será analisada sempre de forma comparativa em relação ao nativo nordestino.

\section{Metodologia e banco de dados}

O rendimento do trabalhador é influenciado por características pessoais, econômicas, sociais e culturais. No caso deste estudo, procura-se estimar de que forma determinados atributos influenciam na determinação do salário do trabalho. Para tal, aplicou-se um modelo econométrico linear tendo como variável dependente o logaritmo natural do rendimento no trabalho principal divido pela jornada de trabalho, mensurada em horas no mês. As demais variáveis - consideradas explicativas - inseridas no modelo são variáveis dummies (assumem valor zero ou um) que indicam a presença ou ausência de determinado atributo, visando captar os efeitos de mudanças nas variáveis explicativas sobre a variável dependente. A escolha das variáveis se justifica na medida em que elas aparecem nos modelos teóricos como determinantes do nível de salário obtido no mercado de trabalho. 
SCHMIDT FILHO, R. \& DO MONTE, P. \& MICELI, M. Um estudo comparativo das disparidades...

Serão estimadas duas equações: a primeira objetiva analisar os componentes do rendimento do trabalhador, procurando-se identificar uma possível disparidade salarial em favor dos paulistas; enquanto a segunda é restrita aos migrantes nordestinos e tem como objetivo maior analisar a influência do tempo de migração na determinação da renda obtida no trabalho principal.

Na primeira equação, a relação funcional usada foi:

$\mathrm{Y}=f(\mathrm{~N}, \mathrm{G}, \mathrm{R}, \mathrm{E}, \mathrm{I}, \mathrm{I} 2, \mathrm{~S} ; \varepsilon)$

Onde, Y representa o logaritmo natural do salário, por hora, obtido no trabalho principal; $\mathrm{G}$ indica o gênero do indivíduo; $\mathrm{R}$ representa a raça do indivíduo; $\mathrm{E}$ indica a escolaridade do indivíduo; I representa a faixa etária do indivíduo; $\mathrm{S}$ indica o segmento de mercado de trabalho onde o trabalhador encontra-se ocupado; $\varepsilon$ são as perturbações aleatórias associadas ao modelo.

Desta forma, as variáveis explicativas envolvidas na estimação do primeiro modelo foram representadas por um conjunto de variáveis indicadoras, detalhadas a seguir:

1. Nativos (N). Foi usada uma variável indicadora que assume valor 1 para paulistas que nunca migraram e o para nordestinos que migraram para São Paulo;

2. Gênero (G). É variável indicadora para os homens, ou seja, assume valor 1 para Homens e o para mulheres;

3. Raça (R). Foi usada uma variável indicadora que assume valor 1 para indivíduos de cor branca e o para indivíduos de demais raças;

4. Escolaridade (E). Usaram-se 2 variáveis indicadores: De 1 a 4 anos de estudo e acima de 4 anos de estudo; sendo a categoria menos de 1 ano de escolaridade usada como referência;

5. Idade (I). As variáveis indicadoras usadas foram: de 21 a 24 , de 25 a 30 , de 31 a 40 , de 41 a 50 e de 51 a 65 anos; sendo usada a variável de 16 a2o anos como referência;

6. Idade2 (I2). Utilizou-se a variável idade ao quadrado;

7. Formal (S). Assume valor 1 para trabalhadores ocupados no setor formal e o para o setor informal.

Assim, a equação estimada será representada por 12 (treze) variáveis indicadoras - estimando-se treze parâmetros, incluindo o termo 
constante. Portanto, a relação funcional apresentada na equação 3.1 pode ser representada da seguinte forma:

$$
Y_{i}=\alpha_{0}+\alpha_{1} N_{1, i}+\alpha_{2} G_{1, i}+\alpha_{3} R_{1, i}+\sum_{j=1}^{4} \alpha_{4} E_{j, i}+\sum_{j=1}^{3} \alpha_{5} I_{j, i}+\alpha_{6} I 2_{1, i}+\alpha_{7} S_{1, i}+\varepsilon_{i}
$$

Onde i representa o i-ésimo trabalhador ( $\mathrm{i}=1,2,3, \ldots, \mathrm{n})$ e $a$ é a constante.

A segunda equação estimada tem como objetivo maior verificar se a permanência no Estado de São Paulo corrobora para aumentos salariais do migrante nordestino - reduzindo, portanto, o diferencial salarial. A relação funcional usada foi:

$\mathrm{Y}=f(\mathrm{~N}, \mathrm{G}, \mathrm{R}, \mathrm{E}, \mathrm{I}, \mathrm{I} 2, \mathrm{~S}, \mathrm{~T} ; \mathrm{e})$

Onde, Y representa o logaritmo natural do salário, por hora, obtido no trabalho principal do migrante nordestino; $\mathrm{G}$ indica o gênero do indivíduo; $\mathrm{R}$ representa a raça do indivíduo; $\mathrm{E}$ indica a escolaridade do indivíduo; I representa a faixa etária do indivíduo; T indica o tempo de permanência no Estado de São Paulo; $\varepsilon$ são as perturbações aleatórias associadas ao modelo. Portanto, comparativamente a primeira relação, acrescentou-se a variável Tempo de Migração (onde foram usadas 2 variáveis indicadores: Migrante de 5 a 9 anos e Migrante acima de 10 anos; sendo a variável migrante o a 4 anos foi utilizada como base) e retirouse a variável Nativo $(\mathrm{N})$, visto que a análise foi restrita aos nordestinos migrantes. Assim, a relação funcional desta segunda equação tem a seguinte representação:

$$
Y_{i}=\alpha_{0}+\alpha_{1} G_{1, i}+\alpha_{2} R_{1, i}+\sum_{j=1}^{4} \alpha_{3} E_{j, i}+\sum_{j=1}^{3} \alpha_{4} I_{j, i}+\alpha_{5} I 2_{1, i}+\alpha_{6} S_{1, i}+\sum_{j=1}^{2} \alpha_{7} T_{j, i}+\varepsilon_{i}
$$

No intuito de avaliar descritivamente e econometricamente a composição da renda obtida no trabalho principal do trabalhador, utilizaram-se as informações contidas nos microdados da PNAD (Pesquisa Nacional por Amostra a Domicílios) de 1995 e 2005, do IBGE (Instituto Brasileiro de Geografia e Estatística). Para a formação do banco de dados do estudo foram criados dois Grupos distintos formados por trabalhadores ocupados no Estado de São Paulo: o primeiro grupo é composto por nativos paulistas que nunca migraram, e o segundo grupo é formado por migrantes nordestinos. 


\section{Informações descritivas dos migrantes nordestinos que residem em São Paulo e dos paulistas que nunca migraram}

A partir da compreensão da existência da segmentação no mercado parte-se para a verificação desta entre dois grupos que participam do mercado de trabalho no Estado de São Paulo. O denominado grupo 1 é constituído por nordestinos que migraram para São Paulo, enquanto o grupo 2 é formado por indivíduos que nasceram em São Paulo e nunca migraram. A finalidade na definição dos grupos é verificar se o Estado de origem do trabalhador tem influência na determinação de salário. Além desta, outras variáveis também serão analisadas através de um estudo descritivo e econométrico.

A amostra inicial foi formada por 43.129 observações (19.521 em 1995 e 23.608 em 2005), das quais a maioria é composta por trabalhadores do gênero feminino $(52,00 \%)$ - fato que pode ser observado no Quadro 3, abaixo ${ }^{4}$. Através da análise por Estado de origem é possível perceber uma predominância das mulheres migrantes em relação aos homens, nos Estados da Bahia, Pernambuco, Maranhão e Paraíba.

TABELA 3 - PERCENTUAL DE HOMENS E MULHERES MIGRANTES POR ESTADO DE ORIGEM - 1995-2005

\begin{tabular}{lcccc}
\hline \multirow{2}{*}{ Estado de Origem } & \multicolumn{2}{c}{1995} & \multicolumn{2}{c}{2005} \\
\cline { 2 - 5 } & Homens & Mulheres & Homens & Mulheres \\
\hline Maranhão & 48,00 & 52,00 & 46,85 & 53,15 \\
Piauí & 54,55 & 45,45 & 44,96 & 55,04 \\
Ceará & 53,85 & 46,15 & 47,78 & 52,22 \\
Rio Grande do Norte & 50,36 & 49,64 & 55,47 & 44,53 \\
Paraíba & 48,77 & 51,23 & 45,12 & 54,88 \\
Pernambuco & 48,10 & 51,90 & 48,21 & 51,79 \\
Alagoras & 50,60 & 49,40 & 44,44 & 55,56 \\
Sergipe & 50,85 & 49,15 & 46,41 & 53,59 \\
Bahia & 47,64 & 52,36 & 46,43 & 53,57 \\
TOTAL & 49,22 & 50,78 & 46,91 & 53,09 \\
\hline PNAD 1995 e 2005 & & & &
\end{tabular}

4 Justo e Silveira Neto (2006) também observaram, em relação ao perfil dos migrantes e nãomigrantes, que o percentual de mulheres na população de migrantes no Brasil como um todo é maior que o percentual de homens. 
Focalizando a análise no ano de 2005 percebe-se que a maioria dos migrantes continua sendo constituída por mulheres, contudo em uma margem bem maior do que a apresentada em 1995. O único estado que apresentou na metade da década de 1990 um maior percentual de homens migrantes foi o Rio Grande do Norte. Uma análise comparativa dos dois quadros nos permite concluir que nesta década houve um acirramento da tendência migratória feminina, com um aumento relativo de 4,50\% na participação feminina, representando uma continuidade no perfil do migrante nordestino verificado no ano de 1995 .

\subsection{Características pessoais}

As informações acerca da idade média e do grau de escolaridade da amostra selecionada estão contidas nos quadros abaixo. O Quadro 4 contém elementos sobre a idade média, por gênero, dos migrantes nordestinos e dos paulistas (nativos). Através do mesmo, verifica-se que, para os paulistas, as mulheres possuem idades em média superiores às idades dos homens, enquanto que para os nordestinos, tal diagnóstico é válido apenas para 2005. Observa-se, também, que o grupo composto pelos migrantes nordestinos possui média inferior as dos nordestinos e que, ao longo do período em análise, ocorreu um aumento da idade média dos migrantes.

TABELA 4 - IDADE MÉDIA DOS MIGRANTES NORDESTINOS E DOS NATIVOS PAULISTAS, EM ANOS - 1995-2005

\begin{tabular}{lcccc}
\hline & \multicolumn{2}{c}{1995} & \multicolumn{2}{c}{2005} \\
\cline { 2 - 5 } & Homens & Mulheres & Homens & Mulheres \\
\hline $\begin{array}{l}\text { Nordestinos } \\
\text { (migrantes) }\end{array}$ & 38,70 & 37,86 & 39,88 & 40,11 \\
$\begin{array}{l}\text { Paulistas } \\
\text { (nativos) }\end{array}$ & 35,28 & 36,15 & 35,38 & 36,45 \\
\hline
\end{tabular}

Fonte: PNAD 1995 e 2005 .

Na tabela 5 busca-se observar o percentual populacional por grupos e gênero que possui mais de 10 anos de estudo. Este dado foi utilizado para indicar o maior grau de escolaridade de um grupo com relação ao outro. Os resultados alcançados apontam para uma elevação nos percentuais para os dois grupos e para os dois gêneros ao longo do período em análise. Verifica-se que as mulheres nos dois grupos e nos dois anos possuem um percentual com mais de 10 anos de estudo superior ao dos homens. Também se verificou que o número de paulistas com 
mais de 10 anos de vida escolar é bem superior ao apresentado pelos nordestinos, indicando, portanto um diferencial considerável de capital humano que pode se refletir em um ganho salarial pró-paulista.

TABELA 5 - PERCENTUAL DA POPULAÇÃO COM MAIS DE 10 ANOS DE ESTUDO - 1995-2005

\begin{tabular}{lcccccc}
\hline População & \multicolumn{3}{c}{1995} & \multicolumn{4}{c}{2005} \\
\cline { 2 - 7 } & Homens & Mulheres & Média & Homens & Mulheres & Média \\
\cline { 2 - 7 } $\begin{array}{l}\text { Nordestinos } \\
\text { (migrantes) }\end{array}$ & 8,46 & 9,61 & 9,04 & 17,60 & 23,82 & 20,90 \\
$\begin{array}{l}\text { Paulistas } \\
\text { (nativos) }\end{array}$ & 30,52 & 32,10 & 31,34 & 51,69 & 53,93 & 52,86 \\
\hline Fonte: PNAD 1995 & 2005 & & & & &
\end{tabular}

\subsection{Situação no mercado de trabalho}

A descrição quantitativa da amostra em respeito a sua situação no mercado de trabalho estão expressas nos quadros 6 a 9. O objetivo é verificar a existência de comportamentos similares entre os indivíduos migrantes e os nativos, bem como perceber a ocorrência de alguma mudança na distribuição destes ao longo do período de análise.

Inicialmente, a tabela 6 procura diferenciar os dois grupos através da situação econômica, ou seja, se economicamente ativo ou inativo. Percebe-se que para os dois anos estudados, o percentual de indivíduos economicamente ativos entre os paulistas é maior que o verificado entre os nordestinos migrantes - tendo esse gap aumentado em 2005 apesar da proximidade dos valores encontrados, indicando que não existe uma diferença significativa de comportamento entre os agentes. O Quadro 6 descreve a situação dos trabalhadores conforme a atividade desempenhada na semana de referência da Pesquisa - PNAD. Assim como na descrição anterior, nota-se que os grupos apresentam comportamentos similares, com uma pequena variação no que respeita ao maior percentual trabalhadores ocupados (e, consequentemente, menor percentual de desocupados) no grupo composto por nativos paulistas. Portanto, no ponto de vista de condição de atividade, os dois grupos apresentaram resultados análogos.

Em relação ao segmento de mercado que o trabalhador encontra-se inserido, observa-se que houve uma deterioração das relações de trabalho para o trabalhador migrante enquanto que para o nativo paulista 
SCHMIDT FILHO, R. \& DO MONTE, P. \& MICELI, M. Um estudo comparativo das disparidades...

houve uma pequena melhora, haja vista que o percentual de trabalhadores ocupados no segmento formal aumentou de $40,8 \%$ para $42,7 \%$, em 2005 .

TABELA 6 - PERCENTUAL DE INDIVÍDUOS MIGRANTES NORDESTINOS E NATIVOS PAULISTAS, POR SITUAÇÃO NO MERCADO DE TRABALHO - 19952005

\begin{tabular}{lcccc}
\hline $\begin{array}{l}\text { Situação no mercado } \\
\text { de trabalho }\end{array}$ & \multicolumn{2}{c}{1995} & \multicolumn{2}{c}{2005} \\
\hline & Nordestinos & Paulistas & Nordestinos & Paulistas \\
\hline Economicamente ativo & 71,9 & 72,3 & 76,0 & 76,7 \\
Ocupados & 66,9 & 67,4 & 67,5 & 68,6 \\
Ocupados no & 40,5 & 40,8 & 37,8 & 42,7 \\
segmento formal & 5,0 & 4,9 & 8,5 & 8,1 \\
Desocupados & 28,1 & 27,7 & 24,0 & 23,3 \\
Inativos & & & &
\end{tabular}

Fonte: PNAD 1995 e 2005.

\subsection{Remuneração Salarial}

Os últimos quadros da análise descritiva enfocam a questão da remuneração salarial, relacionando-a educação e ao tempo de migração. Diante da tabela 7 , desenvolve-se uma análise de informações referente à remuneração dos dois grupos selecionados na pesquisa onde se observa que, tanto para 2005 como para 1995, o salário médio dos nordestinos é inferior ao dos paulistas (em 2005 ele correspondia a 58,37\% do salário dos paulistas, enquanto em 1995 era de $71,14 \%$ ) e que houve um crescimento do salário dos nordestinos no período $(40,57 \%)$ inferior ao observado para o grupo composto por paulistas $(71,31 \%)$. Uma outra forma de analisar o quadro é observando o tempo de permanência do migrante nordestino no Estado de São Paulo. Através deste enfoque é possível notar que o salário médio dos nordestinos apresenta uma tendência de aumento à medida que o tempo de permanência se eleva, indicando assim que o tempo de permanência na região é fator positivo para uma melhor inserção do nordestino no mercado de trabalho de São Paulo e, conseqüentemente, um fator redutor de desigualdade de rendimento. 
SCHMIDT FILHO, R. \& DO MONTE, P. \& MICELI, M. Um estudo comparativo das disparidades...

TABELA 7 - SALÁRIO MÉDIO DOS MIGRANTES NORDESTINOS - POR TEMPO DE PERMANÊNCIA - E NATIVOS PAULISTAS - 1995-2005

\begin{tabular}{lcccc}
\hline $\begin{array}{l}\text { Tempo de } \\
\text { Permanência }\end{array}$ & 1995 & 2005 & 1995 & 2005 \\
\hline & Nordestinos & Nordestinos & Paulistas & Paulistas \\
Até 4 anos & 358,44 & 513,67 & -- & -- \\
De 5 a 9 anos & 406,53 & 638,93 & -- & -- \\
Acima de 10 anos & 525,95 & 709,74 & -- & -- \\
Média & 488,85 & 687,16 & 633,30 & $1.084,90$ \\
\hline
\end{tabular}

Fonte: PNAD 1995 e 2005 .

Na tabela seguinte se efetua uma comparação dos rendimentos por gênero. Observa-se que para os dois anos estudados, os homens, apesar de possuírem um nível de escolaridade inferior, acabam por receber um rendimento superior ao das mulheres. Entre os nordestinos, o salário das mulheres correspondia a cerca de 55,02\% (1995) e 68,14\% (2005) do salário dos homens. Por sua vez, entre os paulistas, a razão era de 57,83\% (1995) e passou para 67,49\% (2005). Ou seja, a discriminação salarial entre os gêneros ocorre de forma independe do Estado de origem do trabalhador.

TABELA 8 - SALÁRIO MÉDIO DOS MIGRANTES NORDESTINOS E DOS NATIVOS PAULISTAS, POR GÊNERO - 1995-2005

\begin{tabular}{lcccc}
\hline População & \multicolumn{2}{c}{1995} & \multicolumn{2}{c}{2005} \\
\hline Homens & Mulheres & Homens & Mulheres \\
\hline Nordestinos & 583,24 & 320,95 & 795,66 & 542,21 \\
Paulistas & 795,08 & 459,85 & $1.260,28$ & 850,66 \\
\hline
\end{tabular}

Fonte: PNAD 1995 e 2005.

Na tabela 9 busca-se observar o salário a partir do investimento em capital humano (aqui representado pela quantidade de anos de estudo) por grupo populacional, bem como analisar se dentro de cada faixa de escolaridade o rendimento aumenta com a permanência do nordestino no Estado de São Paulo. Percebe-se que, de uma forma geral, a tendência foi de crescimento do salário ao longo da permanência do nordestino no mercado de trabalho de São Paulo. Contudo, os nordestinos apre- 
sentam médias de rendimento bastante inferiores as dos paulistas, principalmente para o ano de 2005. As únicas exceções residem no ano de 1995 para as faixas de tempo de permanência inferior a 10 anos e para determinados níveis de escolaridade dos nordestinos, entretanto, como a escolaridade média do nativo paulista é bastante superior a do nordestino, pode-se concluir que, na média, o rendimento do paulista é significativamente superior ao do migrante nordestino.

TABELA 9 - SALÁRIO MÉDIO DOS MIGRANTES NORDESTINOS E DOS NATIVOS PAULISTAS, POR ANOS DE ESTUDO E TEMPO DE PERMANÊNCIA $-1995-2005$

\begin{tabular}{|c|c|c|c|c|}
\hline \multirow{3}{*}{ Grau de Escolaridade } & \multicolumn{4}{|r|}{1995} \\
\hline & \multicolumn{3}{|c|}{ Nordestinos (tempo de permanência) } & \multirow[t]{2}{*}{ Paulistas } \\
\hline & Até 4 anos & $\begin{array}{l}\text { De } 5 \text { a } 9 \\
\text { anos }\end{array}$ & $\begin{array}{l}10 \text { ou } \\
\text { mais anos }\end{array}$ & \\
\hline Menos de 1 ano & 277,44 & 251,96 & 321,78 & 249,95 \\
\hline De 1 a 4 anos & 262,40 & 305,39 & 451,49 & 374,76 \\
\hline \multirow[t]{2}{*}{ Mais de 4 anos } & 456,19 & 500,71 & 673,22 & 789,62 \\
\hline & \multicolumn{4}{|r|}{2005} \\
\hline \multirow[t]{2}{*}{ Grau de Escolaridade } & \multicolumn{3}{|c|}{ Nordestinos (tempo de permanência) } & Paulistas \\
\hline & Até 4 anos & $\begin{array}{l}\text { De } 5 \text { a } 9 \\
\text { anos }\end{array}$ & $\begin{array}{l}10 \text { ou } \\
\text { mais anos }\end{array}$ & \\
\hline Menos de 1 ano & 361,47 & 447,84 & 486,45 & 434,36 \\
\hline De 1 a 4 anos & 468,61 & 517,58 & 599,09 & 630,80 \\
\hline Mais de 4 anos & 552,45 & 715,60 & 814,40 & $1.162,93$ \\
\hline
\end{tabular}

Fonte: PNAD 1995 e 2005.

No ano de 1995, todavia, o salário médio dos paulistas não é superior na maioria dos níveis de escolaridade. Aliás, para todos os níveis a renda dos paulistas não ultrapassa a dos nordestinos com mais de 10 anos de permanência no estado. Resultados similares foram encontrados no estudo de Silveira Neto e Magalhães (2004), onde os autores verificaram a importância dos diferenciais de capital humano para a diferenciação salarial existente entre nordestinos migrantes e nativos paulistas e, também, que de uma forma geral os migrantes apresentam renda inicial menor que os paulistas. 


\section{Fatores explicativos das diferenças salariais entre nordestinos migrantes e paulistas}

Neste tópico busca-se, através de análises econométricas, inferências a respeito dos diferenciais salariais existentes entre os nativos paulistas e os migrantes nordestinos.

A estratégia adotada na primeira regressão foi estimar o rendimento obtido por hora no trabalho principal em função das variáveis explicativas (origem, gênero, raça, idade, nível de escolaridade, segmento de mercado e tempo de migração). Os resultados da estimação da primeira equação estão na tabela 10 e mostram que todas as variáveis apresentaram significância estatística (confirme valor-p descrito). Através da interpretação dos coeficientes estimados é possível concluir que os trabalhadores não-migrantes (paulistas) são mais bem remunerados, comparativamente, aos trabalhadores nordestinos ocupados em São Paulo, mantendo-se constante as demais variáveis, visto que o coeficiente estimado para 2005 foi positivo.

Os demais resultados mostraram a existência de possível discriminação salarial por gênero e raça, onde os homens recebem mais que as mulheres, uma vez que os coeficientes apresentaram sinal positivo, todavia ao compararmos as regressões estimadas para 1995 e 2005, pode-se perceber que ocorre uma redução nos valores dos coeficientes, indicando uma redução na diferenciação salarial por gênero durante o período analisado; fato similar ocorrendo em favor dos trabalhadores da raça branca. No referente à questão da escolaridade, pode-se afirmar que trabalhadores com maior capital humano (medido em anos de estudo) tendem a possuir uma remuneração mais elevada, o mesmo se aplicando em relação as variáveis de classes etárias, onde se percebe idades mais elevadas estão diretamente associadas a maiores salários e que este diferencial de rendimento comparado aos indivíduos de 16 a 20 anos aumentou ao longo do período 1995/2005. Ademais se observa que a faixa mais produtiva em termos de remuneração salarial é faixa que compreende os trabalhadores com idade entre 41 e 50 anos. Com relação à segmentação do mercado, evidencia-se que a inserção ocupacional no segmento formal da economia condiciona o trabalhador a obter maiores rendimentos.

Na segunda regressão buscou-se verificar se a permanência do nordestino no mercado de trabalho paulista, ou seja, se o tempo de migração é fator importante na determinação da renda do trabalho. Este tempo de permanência no mercado representaria uma proxy do maior conhecimento (informação) acerca do mercado de trabalho do Estado de São Paulo, onde os custos iniciais de migração e informação do mercado já estariam sendo diluídos. Os resultados descritos na tabela 11 para a 
SCHMIDT FILHO, R. \& DO MONTE, P. \& MICELI, M. Um estudo comparativo das disparidades...

variável tempo de permanência, em 1995, foram significativos, indicando que os migrantes nordestinos há mais de 10 anos residindo no Estado de São Paulo possuem chances maiores de obter uma renda superior quando comparados aos que estão inseridos no mercado de trabalho de São Paulo há menos de 5 anos. Resultado similar foi observado para o ano de 2005, conforme pode ser visto abaixo.

TABELA 10 - RESULTADOS DA REGRESSÃO LINEAR DOS DETERMINANTES DA RENDA DO TRABALHO PRINCIPAL DOS MIGRANTES NORDESTINOS E DOS NATIVOS PAULISTAS - 1995-2005

\begin{tabular}{llcccc}
\hline \multirow{2}{*}{ VARIÁVEL } & & \multicolumn{2}{c}{1995} & \multicolumn{2}{c}{2005} \\
\cline { 3 - 6 } & & $\begin{array}{c}\text { Valor } \\
\text { Estimado }\end{array}$ & Valor-P & $\begin{array}{c}\text { Valor } \\
\text { Estimado }\end{array}$ & Valor-P \\
\hline (Constante) & & $-1,102$ & 0,001 & $-0,383$ & 0,001 \\
Nativo & Paulista & 0,037 & 0,030 & 0,175 & 0,001 \\
Gênero & Homem & 0,309 & 0,001 & 0,216 & 0,001 \\
Raça & Branca & 0,198 & 0,001 & 0,193 & 0,001 \\
Escolaridade & De1a 4 & 0,328 & 0,001 & 0,102 & 0,001 \\
(anos de & Mais de 4 & 1,023 & 0,001 & 0,686 & 0,001 \\
estudo) & De 21 a 24 & 0,295 & 0,001 & 0,222 & 0,001 \\
& De 25 a 30 & 0,543 & 0,001 & 0,419 & 0,001 \\
Faixa Etária & De 31 a 40 & 0,711 & 0,001 & 0,555 & 0,001 \\
(anos) & De 41 a 50 & 0,873 & 0,001 & 0,590 & 0,001 \\
& De 51 a 65 & 0,717 & 0,001 & 0,549 & 0,001 \\
Idade2 & idade*idade & 0,001 & 0,001 & 0,001 & 0,001 \\
Segmento & Formal & 0,200 & 0,001 & 0,290 & 0,001 \\
\hline
\end{tabular}

Fonte: Elaboração própria a partir dos dados da PNAD (1995 e 2005). 
SCHMIDT FILHO, R. \& DO MONTE, P. \& MICELI, M. Um estudo comparativo das disparidades..

TABELA 11 - RESULTADOS DA REGRESSÃO LINEAR DOS DETERMINANTES DA RENDA DO TRABALHO PRINCIPAL DOS MIGRANTES NORDESTINOS 1995-2005

\begin{tabular}{llcccc}
\hline \multirow{2}{*}{ VARIÁVEL } & & \multicolumn{2}{c}{1995} & \multicolumn{2}{c}{2005} \\
\cline { 3 - 6 } & & $\begin{array}{c}\text { Valor } \\
\text { Estimado }\end{array}$ & Valor-P & $\begin{array}{c}\text { Valor } \\
\text { Estimado }\end{array}$ & Valor-P \\
\hline (Constante) & & $-1,102$ & 0,001 & $-0,383$ & 0,001 \\
Nativo & Paulista & 0,037 & 0,030 & 0,175 & 0,001 \\
Gênero & Homem & 0,309 & 0,001 & 0,216 & 0,001 \\
Raça & Branca & 0,198 & 0,001 & 0,193 & 0,001 \\
Escolaridade & De1a 4 & 0,328 & 0,001 & 0,102 & 0,001 \\
(anos de & Mais de 4 & 1,023 & 0,001 & 0,686 & 0,001 \\
estudo) & De 21 a 24 & 0,295 & 0,001 & 0,222 & 0,001 \\
& De 25 a 30 & 0,543 & 0,001 & 0,419 & 0,001 \\
Faixa Etária & De 31 a 40 & 0,711 & 0,001 & 0,555 & 0,001 \\
(anos) & De 41 a 50 & 0,873 & 0,001 & 0,590 & 0,001 \\
& De 51 a 65 & 0,717 & 0,001 & 0,549 & 0,001 \\
Idade2 & idade*idade & 0,001 & 0,001 & 0,001 & 0,001 \\
Segmento & Formal & 0,200 & 0,001 & 0,290 & 0,001 \\
\hline
\end{tabular}

Fonte: Elaboração própria a partir dos dados da PNAD (1995 e 2005).

\section{Conclusões}

Este artigo procurou enfocar a questão do fluxo migratório de mão-deobra no Brasil, especialmente, sobre o progresso econômico no mercado de trabalho dos migrantes nordestinos no Estado de São Paulo. Para tal, a análise se baseou em dois grupos de indivíduos residentes em São Paulo: um constituído por nordestinos que migraram para o Estado de São Paulo, e outro formado por indivíduos que nasceram no referido Estado e que nunca migraram.

É importante salientar que as conclusões retiradas deste Estudo está restrito aos grupos populacionais com as respectiva metodologia aplicada. Evidentemente que, para se tirar conclusões mais decisivas seria necessário uma análise mais detalhada (incorporando outros anos na base de dados ou até mesmo uma análise por corte visando captar o 
perfil do ondas migratórias); no entanto, acredita-se que os resultados aqui encontrados merecem destaque e atinge o objetivo inicialmente proposto.

Neste contexto, os principais resultados encontrados foram: a) a maioria dos migrantes nordestinos pertencia ao sexo feminino, tanto em 1995 como em 2005 ; $b$ ) as mulheres possuem idades em média superiores às idades dos homens, nos dois grupos, e que o grupo composto pelos paulistas possui média inferior as dos nordestinos, tanto para homens como para mulheres; c) ao longo do período em análise ocorreu um aumento da idade média para todos os grupos e gêneros; $d$ ) as mulheres, nos dois grupos e nos dois anos, possuem um percentual com mais de 10 anos de estudo superior ao dos homens. Também se verificou para os dois anos que o número de paulistas com mais de 10 anos de vida escolar é bem superior ao apresentado pelos Nordestinos; e) há um maior percentual de nordestinos no mercado informal, e o percentual destes neste mercado aumentou na década em estudo; $f$ ) percebe-se que, tanto para 2005 como para 1995, a renda média dos nordestinos é inferior a dos paulistas. Em 2005, ela correspondia a 58,34\% da renda dos Paulistas. Em 1995 era de 71,14\%, ou seja, ao longo da década de estudo aumentou a diferença de salário entre a média dos nordestinos e a dos paulistas; $g$ ) os homens, apesar de possuírem um nível de escolaridade inferior, acabam por receber um rendimento superior ao das mulheres; $h$ ) à medida que os nordestinos permanecem em São Paulo o diferencial de salário em relação aos paulistas nativos diminui; i) à medida que os indivíduos, dos dois grupos aumentam sua escolaridade seus rendimentos aumentam; $j$ ) através do estudo econométrico pode-se corroborar a tese da diferenciação salarial entre o trabalhador nativo de uma região mais desenvolvida e o trabalhador migrante de uma região menos desenvolvida, no caso em questão, do nativo paulista e do migrante nordestino. Os resultados estimados mostraram que esta diferença, embora possa ser explicada na maior qualificação (medida em anos de estudo) dos paulistas, tende a diminuir ao longo do tempo. Assim, quanto maior for o tempo de residência do migrante nordestino no Estado de São Paulo, maior é o seu conhecimento acerca do mercado de trabalho da região, fato que possivelmente contribui para a redução da desigualdade salarial.

\section{Referências}

BEZERRA, F. \& SILVEIRA NETO, R. (2006). "Existe fuga de cérebros no Brasil? Evidências a partir dos Censos Demográficos de 1991 e 2000." Anais do XV Encontro Nacional de Estudos Populacionais.

BORJAS, G. (1999). Heaven's door: immigration policy and the American economy. Princeton, NJ: Princeton University Press. 
SCHMIDT FILHO, R. \& DO MONTE, P. \& MICELI, M. Um estudo comparativo das disparidades...

BRITO, F. \& CARVALHO, J. (2006). "As migrações internas no Brasil: as novidades sugeridas pelos censos demográficos de 1991 e 2000 e pelas PNADs recentes". Parcerias Estratégicas - Edição especial: Análise sobre a Pesquisa Nacional por Amostra de Domicílios (PNAD 2004) 22:441-55.

BIAGIONI, D. (2006). "Determinantes da mobilidade por classes sociais: Teoria do Capital Humano e a Teoria da Segmentação do Mercado de trabalho". URL: http://www.abep.nepo.unicamp.br/encontro2006/docspdf/ ABEP2006_652.pdf. Acesso em 16 de outubro de 2006.

CANO, W. (1977). Raízes da Concentração Industrial em São Paulo. São Paulo: Difel.

CUNHA, J. M. (2006). “A Migração no começo do século 21: continuidades e novidades trazidas pela PNAD 2004”. Parcerias Estratégicas 22:381-440.

GARCIA JR, Afrânio (1989). O Sul: Caminho do Roçado: estratégias de reprodução camponesa e transformação social. São Paulo: Marco Zero; Brasília: Editora Universidade de Brasília: MCT - CNPq.

GOMES FILHO, J. \& CORREIA, C. (1997). "Reestruturação Produtiva sob a Ótica da Teoria da Segmentação do Mercado de Trabalho”. URL: http:// www.race.nuca.ie.ufrj.br/abet/venc/artigos/52.pdf. Acesso em: 16 de outubro de 2006.

IBGE (vários anos). Censo Demográfico.

JUSTO, W. \& SILVEIRA NETO, R. (2006). "Migração Inter-regional no Brasil: Evidências a partir de um Modelo Espacial.” EconomiA 7:163-187.

LIMA, R. (1980). "Mercado de Trabalho: o capital humano e a teoria da segmentação." Pesquisa e Planejamento Econômico 10.

MACEDO, R. (1982). Os Salários na Teoria Econômica. Rio de Janeiro: IPENINPES.

OLIVEIRA, F. (1976). “A Economia Brasileira: crítica à razão dualista”. Seleções CEBRAP 1. São Paulo: Brasiliense.

PASTORE, José (1981). "Mobilidade social sob condições de segmentação do mercado no Brasil”. Estudos Econômicos 11(1).

PIMENTEL, E. (2004). Desigualdades Regionais no Brasil e sua Dinâmica Durante a Década de 1990: um estudo espacializado. Trabalho de Conclusão de Curso (Graduação em Economia): Universidade de São Paulo.

PIORE, M. \& SABEL, C. (1984). The Second industrial divide: possibilities for prosperity. New York: Basic Books.

SCHULTZ, G. (1996). Capital Humano. Rio de Janeiro: Zahar Editores.

SILVA NETTO JÚNIOR, J. (2003). Migrações Interestaduais e Desigualdades Inter-Regionais de Renda no Brasil: Uma Análise por Dados em Painel no Período de 1950-200o. Dissertação de Mestrado, Universidade Federal da Paraíba, Programa de Pós-Graduação em Economia - PPGE.

SINGER, Paul (1981). Economia Política da Urbanização. 8 ed. São Paulo: Brasiliense. 
SCHMIDT FILHO, R. \& DO MONTE, P. \& MICELI, M. Um estudo comparativo das disparidades...

SIFFERT FILHO, N. \& SIQUEIRA, T. (2001). "Desenvolvimento regional no Brasil: tendência e novas perspectivas”. Revista do BNDES 8(16).

SILVEIRA NETO, R. \& MAGALHÃES, A. (2004). "O progresso econômico do migrante em São Paulo: evidências a partir dos censos demográficos de 1991 e 2000." Anais do III Encontro da Associação Brasileira de Estudos Regionais. Belo Horizonte.

STIGLER, George (1962). "Information in the labor market." Journal of Political Economy 70(5):94-105.

TARGINO, Ivan (1987). "Dependência econômica regional e mobilidade interregional”. Revista do Banco do Nordeste 18(3).

TAUBMAN, P. \& WACHTER, M. (1986). "Segmented labor markets.” In ASHENFELTER, O. \& LAYARD, R. (eds). Handbook of Labor Economics. Amsterdam: Elsevier Science Publishers, v. 2.

Recebido em: 11 de março de 2008 Primeira resposta em: 17 de abril de 2008 Aceite em: 03 de junho de 2008 